\section{Commentary: Anterior superior sulcus tumor resection: Easing complexity}

\author{
Nicholas Tingquist, MD, and Jonathan C. Nesbitt, MD
}

Winston Churchill stated, "out of complexities, intense simplicities emerge." Such a quote is applicable to the surgical management of superior sulcus tumors (SSTs). The 3-dimensional network of anatomy in this region coupled with an invasive lung cancer can be quite complex. Although the anatomy of the superior sulcus and thoracic inlet is relatively consistent, concurrent locally invasive tumors are variable. They distort and obscure the regional anatomy and require careful review of radiographs for understanding and surgical planning. The best approach for resection depends not only upon the location of the tumor but also, more importantly, upon the extent of local disease and abutment/invasion of the adjacent skeletal and neurovascular structures.

Hashimoto and Sakamaki ${ }^{1}$ discuss their use of a transclavicular approach for resection of an anterior SST invading the left subclavian vein, anterior first rib, and anterior second rib. ${ }^{1}$ Staging studies confirmed no nodal or metastatic disease. Resection was performed to include the lateral half of the manubrium, medial clavicle, and anterior aspects of the first, second, and third ribs, along with the involved venous structures and en-bloc left upper lobectomy through the anterior thoracotomy. An intercostal nerve graft was employed for phrenic nerve reconstruction, but there are no data or evidence that such a technique succeeds. Articles referenced in the manuscript have extensively discussed the approaches and experiences resecting SSTs, techniques that have been used for decades and provided a roadmap for the resection used by Hashimoto and Sakamaki. ${ }^{1}$

From the Department of Thoracic Surgery, Vanderbilt University Medical Center, Nashville, Tenn.

Disclosures: The authors reported no conflicts of interest.

The Journal policy requires editors and reviewers to disclose conflicts of interest and to decline handling or reviewing manuscripts for which they may have a conflict of interest. The editors and reviewers of this article have no conflicts of interest.

Received for publication Sept 7, 2021; revisions received Sept 7, 2021; accepted for publication Sept 10, 2021; available ahead of print Sept 16, 2021.

Address for reprints: Jonathan C. Nesbitt, MD, Department of Thoracic Surgery, Vanderbilt University Medical Center, 609 Oxford House, 1313 21st Ave South, Nashville, TN 37232 (E-mail: jon.nesbitt@vumc.org).

JTCVS Techniques 2021;10:530-1

2666-2507

Copyright (C) 2021 The Author(s). Published by Elsevier Inc. on behalf of The American Association for Thoracic Surgery. This is an open access article under the CC BY-NC-ND license (http://creativecommons.org/licenses/by-nc-nd/4.0/).

https://doi.org/10.1016/j.xjtc.2021.09.021

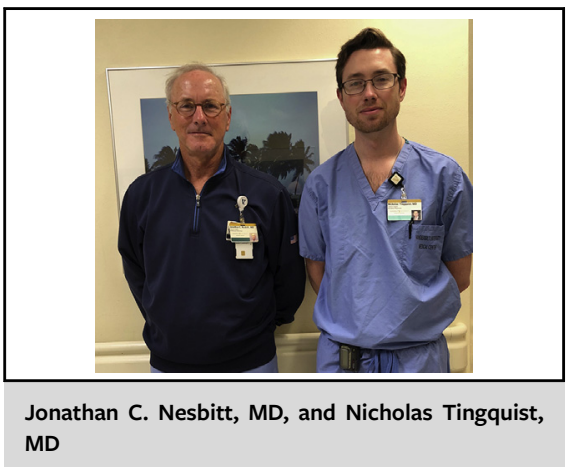

CENTRAL MESSAGE

The transclavicular approach for anterior superior sulcus tumors provides excellent exposure of the critical neurovascular, skeletal, and pulmonary structures for dissection and resection.

Locally invasive SSTs that reside primarily within the anterior superior sulcus are best resected through an anterior approach, as in this case and employed by the authors here. Access to the subclavian vasculature for dissection, resection, and reconstruction is best achieved through this exposure. Posterior SSTs are optimally managed through an extended posterolateral thoracotomy, through which access to the upper thoracic spine and first rib can be achieved, particularly if the spine is invaded by disease. Tumors that bridge both anterior and posterior regions often require a combined approach, although in selected circumstances an anterior approach can provide adequate exposure to the posterior elements to allow complete resection. Surgeons should always be prepared to use a posterior approach, in addition, if posterior components are obscured during anterior dissection.

The authors note the impact of SST resection on shoulder motion. This issue occurs not uncommonly following resection of a posterior SST during which the scalene musculature is transected for exposure and resection of at least the first and second ribs posteriorly. Shoulder support is weakened with resultant drooping. When these elements of the chest wall are preserved, shoulder motion is minimally affected.

We applaud the authors for highlighting the use of this valuable technique in managing tumors of the anterior superior sulcus. Their video and discussion should provide resources for surgeons who encounter this challenging surgical problem. Uncommonly used but valuable surgical techniques as described should be regularly revisited in 
the literature. Familiarity broadens the ability to overcome such complex surgical problems and perhaps brings a better understanding with some degree of intense simplicity.

\section{Reference}

1. Hashimoto K, Sakamaki H. Anterior transclavicular approach for lung cancer invading the superior sulcus. J Thorac Cardiovasc Surg Tech. 2021;10: $527-9$ 